\title{
Utilization of social networks for research by Technical and Vocational Education and Training (TVET) students in South-Eastern Universities in Nigeria
}

\author{
M. E. Ikehi, S. P. Paradang, J. Zimoghen \\ Department of Vocational Teacher Education University of Nigeria, Nsukka, Enugu state \\ Department of Agriculture Education Federal College of Education, Pankshin, Plateau state \\ Department of Vocational/Industrial Education Niger Delta University, Wilberforce Island, Bayelsa state.
}

\begin{abstract}
The study examined the utilization of social networks for research purposes by undergraduate research (project) writing final year TVET students and was conducted in five South-Eastern Universities, in Nigeria. The study adopted descriptive survey research design and the population was comprised of 250 final year TVET students. The instrument for data collection was a structured questionnaire. Three lecturers from the Department of Vocational Teacher Education University of Nigeria, Nsukka validated the instrument. The reliability of the questionnaire items was established using Cronbach alpha method and a co-efficient of 0.78 was obtained. The researchers administered 250 copies of the questionnaire to the respondents with the help of research assistants. Weighted and criterion value mean of 2.50 were used to interpret the result and standard deviation was used to validate the closeness of the respondents from the mean and from each other in their responses. The study identified thirteen social networks, poor utilization and eleven challenges militating against the use of social networks for research activities by TVET students in the South-Eastern Universities in Nigeria. The study recommends the orientation of TVET project writing students and their supervisors on the use of social networks which are usually cheap and time saving communication medium for sharing ideas and project documents during research.

Keywords: Research, Internet, Student, Social Networks, Technical and Vocational Education and Training (TVET), Information
\end{abstract}

\section{Introduction}

Educational attainment is recognized as one of the fundamental indicators of development of nations. To improve the quality and universality of a country's educational system, various countries try to include the use of Information and Communication Technologies (ICTs) in the pedagogical processes. ICTs are described as the integration of various electronic tools that deliver and exchange information to enhance the quality of life that is unconstrained by location, time and distance (Rupert, 2012). ICTs are rooted in the services of a computer. A computer is a device for processing, storing and displaying of information (Britannica, 2010). It refers to any machine that performs tasks under the control of set of instructions called a program. Such devices include laptops, desktop devices, mobile phones (smart phones) and calculations (Encarta, 2009). Others include Personal Data Assistant (PDAs), tablets, palm-tops, electronic note pads and any electronic information and communication gadget. Exchange of information between computers over the distance is made possible through the internet.

Internet is the connection of computers communicating simultaneously for the exchange of information. It refers to computer-based global information system. The Internet is composed of many interconnected computer networks (Encarta, 2009). Each network may link tens, hundreds, or even thousands of computers, enabling them to share information at processing power. The Internet has made it possible for people all over the world to communicate with one another effectively and inexpensively. Internet increases people's social capital, increasing contact with friends and relatives who live nearby and far away (Barry, 2001). Unlike traditional broadcasting media, such as radio and television, the Internet does not have a centralized distribution system (Encarta, 2009). Instead, an individual who has Internet access can communicate directly with anyone else, post information for general consumption, retrieve information, use distant applications and services. Internet services provide opportunity for social networking.

Social networks are computer-based online community of individuals (friends) who exchange messages, share information and, in some cases, cooperate on joint activities (Britannica, 2010). Social networks link people, organizations and knowledge with others over physical boundaries (Barry, 2001). The author stressed that they are social institutions removing isolated livelihood as it is being integrated into everyday lives. Most social networks communicate via status-message updates and exchange data in text, picture and video form. A basic social networking software/site allows friends to comment on one another's profiles, send private messages within the network, and traverse the extended web of friends visible in each member's profile. Examples of prominent social networks include Facebook, Twitter, Instagram, Pinterest, Blackberry Messenger, Cyworld, Bebo, MySpace, YouTube, Live!, Friendster, Skype, Flickr, Google ${ }^{+}$, Yahoo! Messenger, Beehive, 
Whatsapp, 2go, Hi5, and many others (Morris \& Horvitz, 2007; Danah \& Nicole, 2007; DiMicco, Millen, Geyer, Dugan, Brownholtz \& Muller, 2008; Solis, 2008; Morris \& Teevan, 2009; Britannica, 2010; Meredith, Jaime \& Katrina, 2010). Operating a social network service involve the creation and maintenance of a unique personal profile that is linked with other members thus enabling a user to specifically connect and communicate with other users that are linked to the specific network (mostly) through the internet (Britannica, 2010; Meredith et al 2010). The resulting network of "friends" or "contacts" with similar interests, business goals, or academic courses has replaced for many people, especially the younger ones, the older concepts of community.

Social networking sites (SNSs) are often thought of as places to catch up on the personal information and current activities of public ties. In addition to societal and playful uses, many users are harnessing their social networks as sources of information and productivity (DiMicco et al 2008). Since their inception with the launching of 'SixDegrees.com' as the first social network in1997 (see appendix A for the timeline initiation of subsequent social networks), social networking sites have attracted millions of users, many of whom have integrated these sites into their daily practices (Danah \& Nicole, 2007). Social networking services (software and site) provide a source of information for research that is complementary to that provided by search engines, although the former provide information that is highly tailored to an individual and comes from a direct source, while the latter provides objective data are from a variety of sources on a related of topics (Meredith et al 2010). SNSs are about dialog - two way discussions bringing people together to discover and share information (Solis, 2008). Posting to a social network site is like speaking to an audience from behind a curtain.

Broadcasting a question to one's social network is one way to find information online for research and information gathering while conducting studies (Meredith et al 2010) which encourages collaborative and social search. Collaborative search is a social hunt where several users share information need and work together to fulfill that need (Morris \& Horvitz, 2007; Morris \& Teevan, 2009). The term social search refers broadly to the process of finding information online with the assistance of communal resources, such as asking friends, reference librarians, or unknown persons online for assistance (Meredith et al 2010). The author further explained that social search may also involve conducting a quest over an existing database of content previously provided by other users, such as probing over the collection of public Twitter posts, or searching through an archive of questions and answers. Some of the social networks, like e-mails, allow the attachment and sending of files in various document formats to the other party in the network. Some researchers have built special tools to integrate social information with search engine use, such as HeyStaks a browser plug-in that enables users to mark search results as relevant; these results are then boosted in the rankings of socially connected users who do searches on similar topics (Smyth, Briggs, Coyle \& O'Mahoney, 2009). People ask questions via social network status messages to enlist the help of others, and the information need belongs solely to the question asker (Morris \& Horvitz, 2007). However, the use of social networks poses such challenges as security threat to personal information, distractions while using the social network and obtaining of unverifiable data (Meredith et al 2010; ComputerWeekly, 2014). Changes in interaction patterns and social connections are already evident among young people, who are the heaviest users of these sites (Solis, 2008).

Internet users under 50 years of age are particularly likely to use a social networking site of any kind, and those 18-29 years are the most likely of any demographic cohort to do so (Maeve \& Joanna, 2013). Young adults in post-secondary education often use social networking to discuss schoolwork and share discussions about assignments. A December 2008 survey by the Pew Internet Project found 35\% of adult internet users in the United States have a profile on a social network, as do $65 \%$ of teens (Maeve \& Joanna, 2013). Students arrive at universities with variety of backgrounds, interests, and abilities.

However, at final state of university education, a student is expected to conduct a research as a requirement for the award of sourced degree and as a way of improving the body of knowledge in the student and the school. Research is a logical and systematic process of finding out solution to a problem (Anaekwe, 2007; Uzoagulu, 2011). It involves the envisaging of a problem, gathering of review/literature of such or related problem, determining the design or proposed pattern to come about the solution, collection of data, organization of data, analysis of data, interpretation of data, and conclusion with the solution to the envisaged problem (Uzoagulu, 2011). Research work is part of every tertiary educational system including Technical and Vocational Education \& Training (TVET).

Technical and Vocational Education \& Training (TVET) is a comprehensive term referring to those aspects of general educational processes that involve, the study of technologies and related sciences, and the acquisition of practical skills, attitudes, understanding and knowledge relating to occupations in various sectors of economic and social life particularly as it pertains to the world of work (TVETpedia, 2013). TVET refers to all deliberate interventions instituted or created to make learners more productive (or simply adequately productive) in designated areas of economic activities and occupation (Karen, Jason, \& Annette, 2008). TVET learning experiences are enshrined in TVET courses such as Agriculture, Art, Business, Computer, Home Economics, Industrial, Music- Education, among others. TVET learning and research process is not devoid of ICTs especially internet based services such as social networks as they foster the spread of information as well 
as the collaboration of trends in TVET. The use of social networks provide TVET students and researchers with the opportunity of communicating with research supervisors, course mates, and friends of share or varied educational background for correction, suggestion and information without distance being a hindrance to effective research work even in South-Eastern Universities in Nigeria. Thus this study is aimed at determining the:

1. Statistical distribution of undergraduate final year TVET students who utilize social network in SouthEastern Universities in Nigeria.

2. Utilized social networks in South-Eastern Universities in Nigeria.

3. Extent of utilization of social networks for research in South-Eastern Universities in Nigeria.

4. Challenges associated with the use of social networks for research in South-Eastern Universities in Nigeria.

\section{Methodology}

The study adopted descriptive survey research design and was carried out in five (5) public universities in the South-Eastern part of Nigeria where the use of electronic gadgets are freely allowed and as well offer TVET courses. The five (5) universities are: University of Nigeria, Nsukka (UNN), Enugu State University of Science and Technology, Enugu (ESUT), Nnamdi Azukiwe University, Awka (UNIZIK), Ebonyi State University, Abakaliki (EBSU), and Michael Opkara University of Agriculture, Umudike (MOUAU). The target population for the study was made up of final year undergraduate TVET students who have begun their research (project) writing and owns any internet based electronic gadget. A total of 50 students were purposively selected from each university, giving a sample size of 250 students that participated in the study. The instrument for data collection was a structured questionnaire developed from the literature reviewed for the study. The instrument was divided into two parts (I \& II): part I was concerned with the statistical distribution of undergraduate final year TVET students who utilize social networks; part II had three sections (A, B, C), each corresponding to objective 2, 3, and 4 respectively. Each item in section $\mathrm{A}$ and $\mathrm{C}$ was assigned four response options of Strongly Agree $(S A=4)$, Agree $(A=3)$, Disagree $(D=2)$ and Strongly Disagree $(S D=1)$ while each item in section $B$ was assigned four response options of Highly Extent (HE=4), Moderate Extent (ME=3), Low Extent (LE=2) and No Extent $(\mathrm{NE}=1)$. The instrument was face-validated by three experts from the department of Vocational Teacher Education (VTE) at the University of Nigeria, Nsukka. The reliability of the instrument was calculated using the Cronbach alpha method which yielded a co-efficient of 0.78 . The researchers with the help of two research assistance administered 250 copies of the questionnaire and all were successfully retrieved for data analysis. Statistical tools such as frequency $(\mathrm{F})$, simple percentage $(\%)$, mean $(\bar{x})$ and standard deviation $(\sigma)$ were utilized in the study. Weighted and criterion value mean of 2.50 were used to interpret the result and standard deviation was used to validate the closeness of the respondents from the mean and from each other in their responses. For section A, any item with mean value equal to or greater than 2.50 was regarded as utilized (UT) while items with mean value less that 2.50 was regarded as not utilized (NUT) by the respondents. For section $\mathrm{B}$, any item that falls within real limit above 3.50, 2.50-3.49, 1.50-2.49 and below 1.49 was regarded as High Extent (HE), Moderate Extent (ME), Low Extent (LE) and No Extent (NE) of use, respectively. For section C, any item with mean value equal to or greater than 2.50 was regarded as a hindrance thus a challenge $(\mathrm{Ce})$ to effective use of social networks as research tool while items with mean value less than 2.50 was not a hindrance thus not a challenge (NC).

\section{Findings} 4.

The findings of the study were obtained from the research questions answered and reported in tables 1 -

Table 1: Statistical distribution of respondents who utilize social networks in South-Eastern Universities in Nigeria

$\mathrm{N}=250$

\begin{tabular}{|c|c|c|c|c|}
\hline \multirow[t]{3}{*}{ Gender } & \multicolumn{3}{|c|}{ Age range } & \multirow[b]{2}{*}{ Total } \\
\hline & $18-22$ & $23-27$ & Above 27 & \\
\hline & $\mathrm{F} \quad(\%)$ & $\mathrm{F} \quad(\%)$ & $\mathrm{F} \quad(\%)$ & $\mathrm{F} \quad(\%)$ \\
\hline Female & $71(54.2)$ & $52(39.7)$ & $8(6.1)$ & $131(52.4)$ \\
\hline Male & $51(42.9)$ & $56(47.0)$ & $12(10.1)$ & $119(47.6)$ \\
\hline Total & $122(48.8)$ & $108(43.2)$ & $20(8.0)$ & $250(100)$ \\
\hline
\end{tabular}


Figure 1: $\quad$ Frequency distributions chat of undergraduate final year TVET students who utilize social networks in South-Eastern Universities in Nigeria

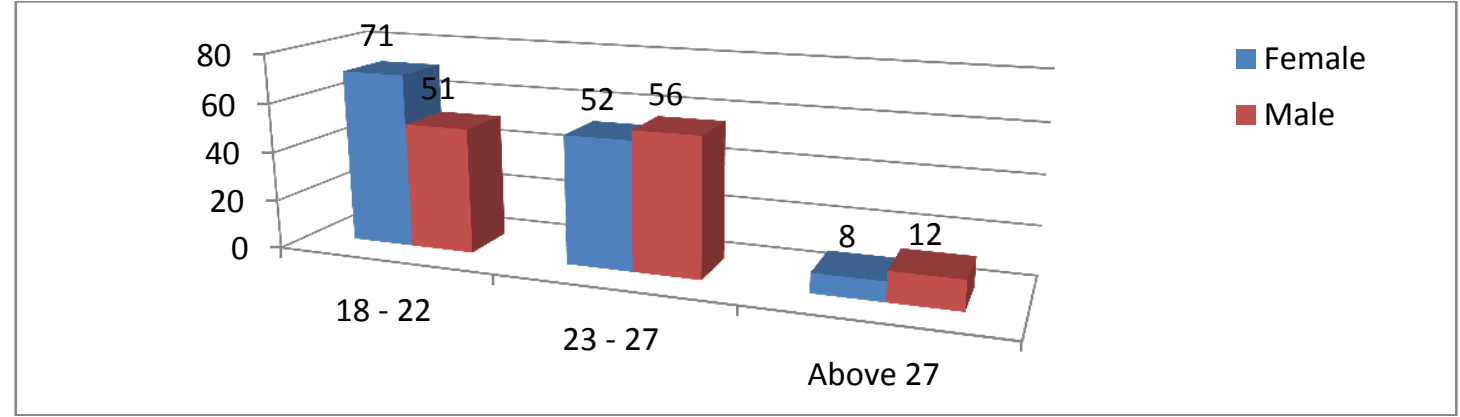

Data in figure 1, as indicated in table 1, reveals that the highest number $(71,54.2 \%$ of females) of undergraduate TVET final students who utilize social networks are females who are within the $18-22$ years age range. Others include males of $23-27$ years $(56,47.0 \%$ of males), females of $23-27$ years $(52,39.7 \%$ of females), males of $18-22$ years $(51,42.9 \%$ of males. The least groups are above 27 years of age of both male $(12,10.1 \%$ of males $)$ and females $(8,6.1 \%$ of females $)$.

Table 2: Mean ratings of the respondents on utilized social networks in South-Eastern Universities in Nigeria

\begin{tabular}{|c|c|c|c|c|}
\hline S/NO & Research utilizable social networks & $\bar{x}$ & $\sigma$ & Remark \\
\hline 1. & Blackberry Messenger (BBM) & 3.43 & 0.54 & UT \\
\hline 2. & Whatsapp & 3.31 & 0.86 & UT \\
\hline 3. & Facebook & 3.62 & 0.62 & UT \\
\hline 4. & Twitter & 3.22 & 1.01 & UT \\
\hline 5. & Badoo & 2.68 & 0.98 & UT \\
\hline 6. & Orkut & 2.13 & 0.77 & NUT \\
\hline 7. & Linkedin & 2.34 & 1.11 & NUT \\
\hline 8. & Yahoo! Messenger & 3.11 & 0.87 & UT \\
\hline 9. & 2go & 2.96 & 1.08 & UT \\
\hline 10. & Google $^{+}$ & 2.78 & 1.00 & UT \\
\hline 11. & Tvetpedia & 2.84 & 0.78 & UT \\
\hline 12. & Instagram & 2.51 & 0.91 & UT \\
\hline 13. & Friendster & 2.39 & 0.85 & NUT \\
\hline 14. & Skype & 3.23 & 1.12 & UT \\
\hline 15. & Flickr & 2.11 & 0.92 & NUT \\
\hline 16. & Beehive & 1.99 & 0.87 & NUT \\
\hline 17. & Bebo & 2.12 & 1.00 & NUT \\
\hline 18. & Cyworld & 2.01 & 0.76 & NUT \\
\hline 19. & MySpace & 2.63 & 0.93 & UT \\
\hline 20. & YouTube & 3.34 & 0.59 & UT \\
\hline 21. & Live & 2.15 & 1.04 & NUT \\
\hline 22. & $\mathrm{Hi} 5$ & 2.55 & 0.76 & UT \\
\hline 23. & Pinterest & 2.41 & 0.99 & NUT \\
\hline
\end{tabular}

Data on table 2 revealed that fourteen items had their mean values ranged from 2.51 to 3.62 which are above the criterion value point of 2.50 , indicating that the social networks are utilized by the respondents. The remaining nine items had mean values below 2.50, indicating that the respondents poorly or do not use the social networks. The standard deviation of all the items ranged from $0.54-1.12$ indicating that the respondents were not far from the mean and from one another in their response.

Table 3: Mean ratings of the extent of utilization of social networks for research in South-Eastern Universities in Nigeria $\mathbf{N}=\mathbf{2 5 0}$

\begin{tabular}{|c|c|c|c|c|}
\hline S/NO & Utilization of social networks & $\bar{x}$ & $\sigma$ & Remark \\
\hline 1. & To source/generate research topics by asking friends/colleagues & 2.51 & 0.88 & $\mathrm{ME}$ \\
\hline 2. & Modify research topics & 2.11 & 1.01 & $\mathrm{LE}$ \\
\hline 3. & Source for information for background and literature of the study & 2.12 & 1.00 & LE \\
\hline 4. & Source for data for accurate format for fact presentation & 2.78 & 0.98 & $\mathrm{ME}$ \\
\hline 5. & Get recent citation & 2.43 & 0.99 & LE \\
\hline 6. & Ask friends for updated theories relevant to the study & 2.53 & 0.86 & ME \\
\hline 7. & $\begin{array}{l}\text { Source for advice on how to frame the purpose of the study, research } \\
\text { questions and the hypothesis }\end{array}$ & 1.32 & 0.97 & $\mathrm{NE}$ \\
\hline 8. & Send/receive partly or fully completed research work to friends and superiors & 1.92 & 1.21 & LE \\
\hline
\end{tabular}




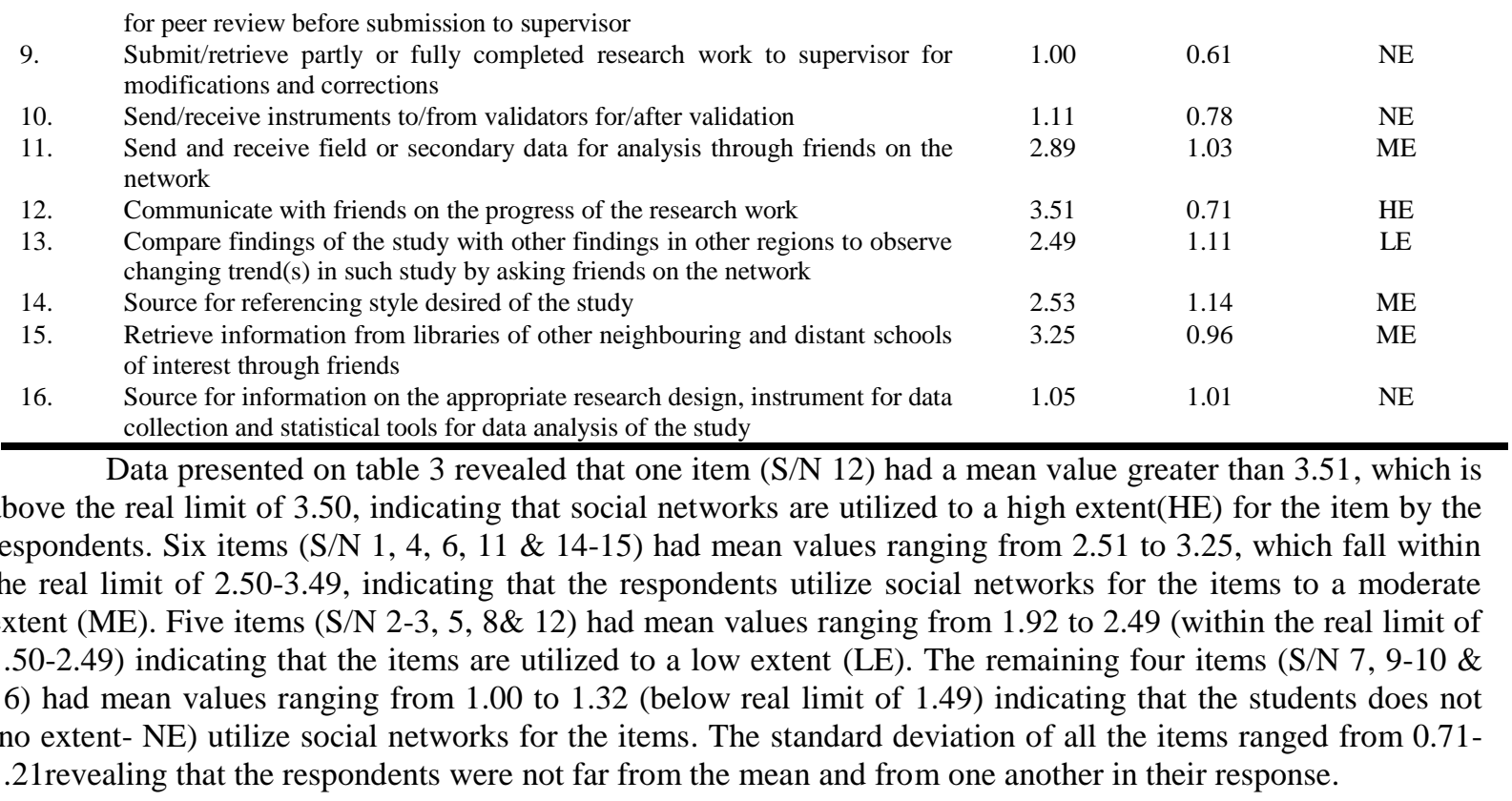

Table 4: Mean ratings of the respondents on the challenges militating against the effective use of social network for research by TVET final year students. $\mathbf{N}=\mathbf{2 5 0}$

\begin{tabular}{|c|c|c|c|c|}
\hline S/NO & Challenges of effective use of Social networks & $\bar{x}$ & $\sigma$ & Remark \\
\hline 1. & $\begin{array}{l}\text { Poor orientation among TVET students/supervisors on the use of social } \\
\text { network for research work }\end{array}$ & 3.11 & 0.89 & $\mathrm{Ce}$ \\
\hline 2. & High internet charges in the country & 3.43 & 0.74 & $\mathrm{Ce}$ \\
\hline 3. & Poor internet services by network provides (available but slow) & 2.65 & 0.76 & $\mathrm{Ce}$ \\
\hline 4. & Infrequent internet services (rarely available) & 2.48 & 0.68 & $\mathrm{NC}$ \\
\hline 5. & High cost of internet enable devices & 2.87 & 0.92 & $\mathrm{Ce}$ \\
\hline 6. & Limited supply of internet enabled devices to students for research & 3.00 & 1.12 & $\mathrm{Ce}$ \\
\hline 7. & Dominance of unverified information from social networks & 2.99 & 0.54 & $\mathrm{Ce}$ \\
\hline 8. & Lack of skills in the operation of internet enable devices & 2.57 & 0.61 & $\mathrm{Ce}$ \\
\hline 9. & Limited availability of concise TVET information on social networks & 2.68 & 1.11 & $\mathrm{Ce}$ \\
\hline 10. & Unsteady/poor power supply to power the internet enabled devices & 3.21 & 0.83 & $\mathrm{Ce}$ \\
\hline 11. & High occurrence/number of distractions while using the social network & 3.45 & 0.59 & $\mathrm{Ce}$ \\
\hline 12. & Poses security threat to personal information and privacy & 3.38 & 0.44 & $\mathrm{Ce}$ \\
\hline
\end{tabular}

From table 4 eleven (S/N 1-3 \& 5-12) out of twelve items had mean values ranging from 2.65 to 3.38 which is above the mean criterion value mean of 2.50 thus accepted as challenges (Ce) inhibiting effective use of social networks by final year TVET project writing students in the South Eastern Universities in Nigeria. One item ( $\mathrm{S} / \mathrm{N} 4$ ) had mean value of 2.48 (which is below the criterion value mean of 2.50) indicating that the item is not a challenge (NC) thus not a factor militating against the utilization of social networks. The standard deviation of all the items ranged from 0.44-1.12 revealing that the respondents were not far from the mean and from one another in their response.

\section{Discussion of Findings}

The findings of the study in table one reveals that female $(131,52.4 \%)$ TVET final year students are slightly higher than the males $(119,47.6 \%)$. However, majority of social network utilizers are within the age range 18-22 (122 out of $250,48.8 \%$ ) and 23-27 (108 out of $250,43.2 \%)$, accounting for $92 \%$ of the respondents. This finding is line with Maeve and Joanna (2013) who stated that internet users of 18-29 years of age are the most likely of any demographic cohort to utilizer social networks.

Findings in table 2 identified thirteen out of twenty three social networks utilized by TVET students in the South-Eastern Universities in Nigeria. These include Blackberry Messenger (BBM), Whatsapp, Facebook, Twitter, Badoo, Yahoo! Messenger, Skype, 2go, YouTube, Google+, Instagram and Tvetpedia among others. This finding corresponds with that of many authors who enlisted Facebook, Twitter, Instagram, Blackberry Messenger, YouTube, Skype, Google+, Yahoo! Messenger, Whatsapp, 2go, and many others as available and utilized social networks (Morris \& Horvitz, 2007; Danah \& Nicole, 2007; DiMicco, Millen, Geyer, Dugan, Brownholtz\& Muller, 2008; Solis, 2008; Morris \&Teevan, 2009; Britannica, 2010; Meredith, Jaime \& Katrina, 2010) 
Findings of the study in table 3 revealed that final year project writing TVET students utilize social network for communicate with friends on the progress of the research work to a high extent and utilize social network to source/generate research topics by asking friends/colleagues, ask friends for updated theories relevant to the study, send/receive field or secondary data for analysis through friends on the network, source for up-to-date referencing style desired of the study, and retrieve information from libraries of other neighbouring and distant schools of interest through friends, to a moderate extent. From the ongoing, it is obvious that the use of social networks is still limited within the realms of friends. As in the view of Solis (2008), Britannica (2010) and Meredith et al (2010) who explained social networks as a two way discussions bringing people (friends) together to discover and share information. The findings on the table also revealed that the respondents utilize social networks for research purposes such as modify research topics, source for information for literature of the study, get recent citation, and send/receive partly or fully completed research work to friends and superiors for peer review before submission to supervisor at a low extent, and does not (to no extent) utilize socials networks for important research activities such as sourcing for advice on how to frame purpose of the study, research questions and hypothesis, submitting/retrieving partly or fully completed research work to supervisor for modifications and corrections, sending/receiving instruments to/from validators for/after validation, and sourcing for information on the appropriate research design, instrument for data collection and statistical tools for data analysis of the study. This finding, of poor utilization, negates the views of Meredith et al (2010) and Maeve and Joanna (2013) who described social networks as a tool for souring information for study and solving assignments.

The study in table 4 identified eleven challenges militating against the effective use of social networks for research by final year TVET students in South-Eastern Universities in Nigeria, which include poor orientation among TVET students/supervisorson the use of social network services for research work, high internet charges in the country, dominance of unverified information from social networks, limited availability of concise TVET information on social networks, high occurrence/number of distractions while using the social network, and posing security threat to personal information and privacy, among others. These findings goes along with the view of Meredith et al (2010) and ComputerWeekly (2014) that opined that the use of social networks poses such challenges as threat to personal information, distractions while using the social network and obtaining of unverifiable data.

\section{Conclusion}

Social networks are changing the online communication pattern in the society and the trend of change is on the fast lane. It has become imperative to adopt the tool as a means of communication and information gathering in the pedagogical system, especially in the research area. The study therefore recommends: (1) the orientation of TVET project writing students and their supervisors on the use of social networks which are usually cheap and time saving communication medium for sharing ideas and project documents, (2) setting of TVET-based social networks aimed at providing verifiable data/information for TVET students, (3) provision of internet enabled devices for TVET students to encourage digitalization of research and its procedures

\section{Reference}

[1]. Anaekwe, C. M. (2007).Basic research methods and statistics in education and social sciences. Sofie Publicity and Printry Ltd. Onitsha, Nigeria. 978-35100-9-6

[2]. Avril, J.B. (2013). ICTs and TVET. Retrieved 24th November, 2013 from http://www.unevoc.unesco.org/go.php?q=page_ICTs_tvet

[3]. Barry, W. (2001). Computer networks as social networks. Science, 293: 2031-2034.

[4]. Britannica.(2010). Social network Encyclopædia Britannica.Encyclopaedia Britannica Student and Home Edition. Chicago, USA.

[5]. Computerweekly. (January, 2014). Social media: A security challenge and opportunity. Retrieved $28^{\text {th }}$ January, 2014, from http://www.computerweekly.com/features/social-media-a-security-challenge-and-opportunity

[6]. Danah, M. B. \& Nicole B. E. (2007). Social Network Sites: Definition, History, and Scholarship. Journal of Computer-Mediated Communication, 13: (1) 210-230.

[7]. DiMicco, J., Millen, D., Geyer, W., Dugan, C., Brownholtz, B. \& Muller, M. (2008).Motivations for Social Networking at Work.CSCW, 8: 711-720.

[8]. Karen, S., Jason, S. \& Annette, K. (2008).The Effects of the Use of Interactive Whiteboards on Student Achievement.Research Center for Educational Technology. Kent State University, USA.

[9]. Maeve, D. \& Joanna, B. (2013). The Demographics of Social Media Users - 2012. Pew Research Center's Internet \& American Life Project 1615 L St., N.W., Suite 700 Washington, D.C. 20036. Retrieved 22 $2^{\text {rd }}$ January, 2014, from http://pewinternet.org/Reports/2013/Social-media-users.aspx

[10]. Meredith, R. M., Jaime, T. \& Katrina P. (2010). What do people ask their social networks, and why? A survey study of status message q\&a behavior. Microsoft Research Redmond, WA, and Massachusetts Institute of Technology Cambridge, MA, USA.

[11]. Morris, M.R. \& Horvitz, E. (2007).SearchTogether: An interface for collaborative Web search. UIST, 3-12.

[12]. Morris, M.R. \&Teevan, J. (2009). Collaborative search: who, what, where, when, and why. Morgan \& Claypool. In: Meredith, R. M., Jaime, T. \& Katrina P. (2010). What do people ask their social networks, and why? A survey study of status message q\&a behavior. Microsoft Research Redmond, WA, and Massachusetts Institute of Technology Cambridge, MA, USA.

[13]. Rupert, M. (2012).The importance of ICTs in TVET.Center for lifelong learning research and development.The Hong Kong Institute of Education. 
[14]. Smyth, B., Briggs, P., Coyle, M. \&O“Mahoney, M. (2009). Google shared: A case study in social search. UMAP. In: Meredith, R. M., Jaime, T. \& Katrina P. (2010). What do people ask their social networks, and why? A survey study of status message q\&a behavior. Microsoft Research Redmond, WA, and Massachusetts Institute of Technology Cambridge, MA, USA.

[15]. Solis, B. (2008). Introducing the conversation prism. Retrieved 22rd January, 2014, from http://www.briansolis.com/2008/08/introducing-conversationprism.html

[16]. TVETpedia (2013). What is TVET? Retrieved 4th November, 2013, from http://www.unevoc.unesco.org/tvetipedia.0.html?\&tx_drwiki_pi1\%5Bkeyword\%5D=TVET.

[17]. Uzoagulu, A. E. (2011). Practical guide to writing research project report in tertiary institutions.Cheston Publishers. Enugu, Nigeria

[18]. Encarta. (2009). Internet. Microsoft ® Encarta ® 2009. ㄷ 1993-2008 Microsoft Corporation.

\section{Appendix A}

Figure 2:Timeline of the launch dates of many major SNSs and dates when community sites re-launched with SNS features

\section{Launch Dates of Major Social Network Sites}

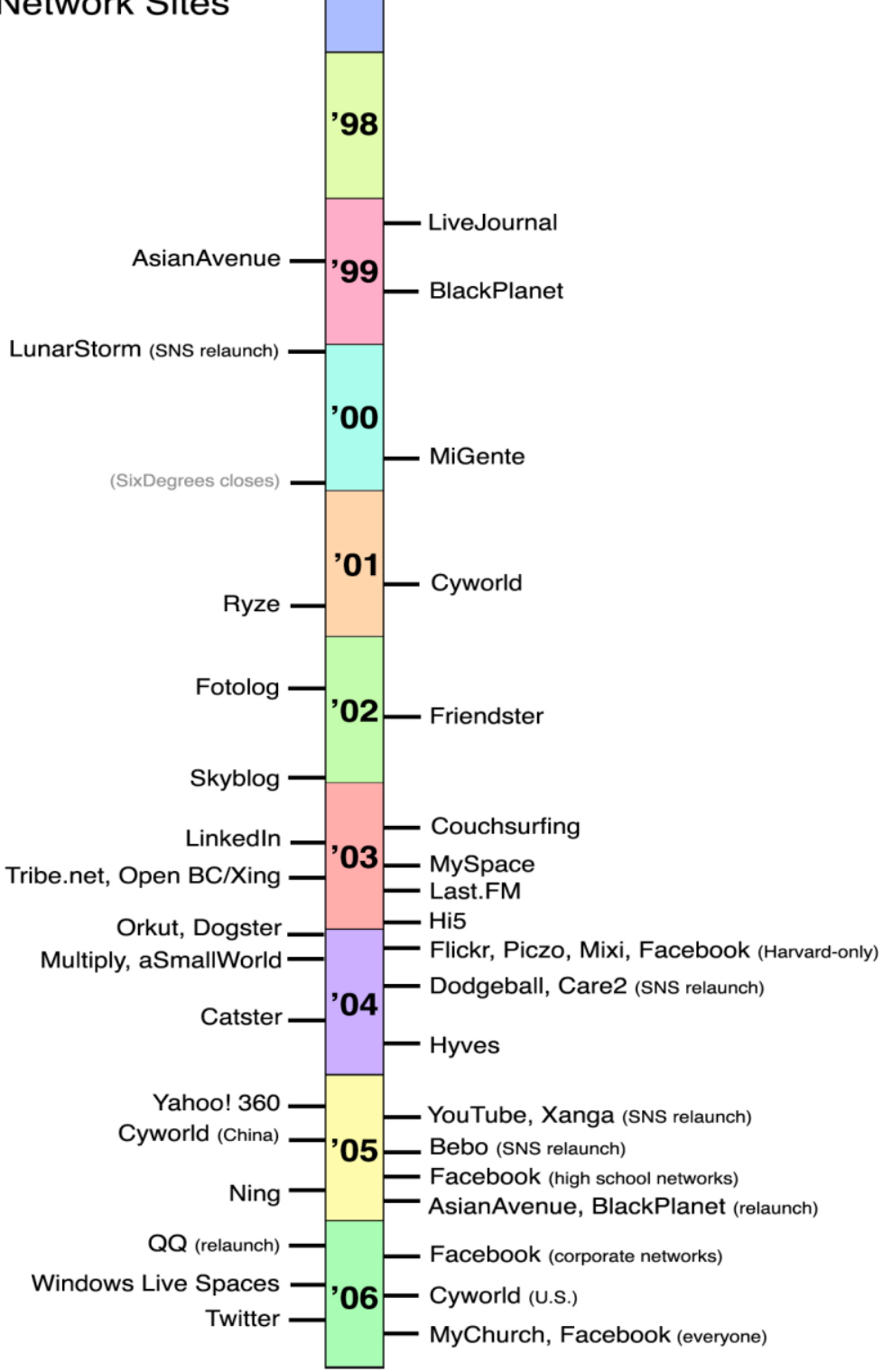

Source; Danah\& Nicole (2007). 